\title{
Clinical Evaluation of Gingival Thickness and Width according to Dental Arch and Location in Pigmented and Nonpigmented Gingiva
}

\author{
Divya Saxena ${ }^{1}$ Rosheni A. Mamen ${ }^{1} \quad$ Sanjeev Jain ${ }^{1} \quad$ Gaurav Pandav ${ }^{1} \quad$ Riddhi Aggarwal $^{1} \quad$ Shreanshi Jolly \\ ${ }^{1}$ Department of Periodontology, Guru Nanak Dev Dental College \& \\ Address for correspondence Divya Saxena, H.no.29/5-B, \\ Research Institute, Sunam, Punjab, India \\ Sodhian Street, Malgodham Road, Dhuri, Punjab 148024, India \\ (e-mail: drdivyasaxena2254@gmail.com).
}

Dent J Adv Stud:2021;9:31-35

\begin{abstract}
Introduction The present study aimed to clinically evaluate and compare the variations in gingival thickness and width of keratinized gingiva according to the dental arch and location in pigmented and nonpigmented gingiva.

Materials and Methods A total of 240 sites from systemically healthy subjects were selected and divided into two groups; Group 1 (pigmented gingiva) and group 2 (nonpigmented gingiva). After the initial visit of scaling and root planning, the gingival thickness was evaluated mid-buccally in the attached gingiva, that is, the center of the mucogingival junction and free gingival groove, and at the base of the interdental papilla. Similarly, the gingival width was measured as the distance from the gingival margin to the mucogingival junction. A single calibrated examiner recorded the measurements using the digital vernier caliper with a resolution of $0.01 \mathrm{~mm}$.

Results Gingival thickness and width were found to be significantly higher in pigmented than nonpigmented gingiva. Also, the maxillary arch was found to have thicker and wider gingiva than the mandibular arch in both the groups. The gingival thickness was found to be maximum in central incisor and minimum in canine in both the groups. However, the width of keratinized gingiva was found to be maximum in lateral

Keywords

- gingival biotype

- gingival thickness

- gingival width

- pigmentation incisor in group 1 (pigmented) and central incisor in group 2 (nonpigmented) and minimum in canine in both the groups.

Conclusion A significant positive correlation in gingival thickness and width was observed according to dental arch and location in both pigmented and nonpigmented gingiva.
\end{abstract}

\section{Introduction}

Knowledge is the gateway to the solution of a problem. Nowadays, esthetics is on the top priority of the patients seeking dental care, and from a clinician's point of view, a sound knowledge of periodontal anatomy is necessary to understand the behavior of the periodontal tissues to various physical, chemical, and thermal insults, ${ }^{1}$ implant, ${ }^{2,3}$ and orthodontic treatment. ${ }^{4}$

published online

October 29, 2020
DOI https://doi.org/

$10.1055 / \mathrm{s}-0040-1719225$

ISSN 2321-1482.
There are a considerable intra- and interindividual variations in both the width and thickness of the facial gingiva, giving rise to the assumption that different gingival phenotypes might exist in any adult population. Joshi et al in 2016 mentioned two variants of gingival biotype, that is, thick and thin gingival biotype. Thick biotype resists trauma and subsequent recession, enables tissue manipulation, promotes creeping attachment, improves implant aesthetics, exhibits less clinical inflammation, and renders predictable

(C2020. Bhojia Dental College and Hospital affiliated to Himachal Pradesh University.

This is an open access article published by Thieme under the terms of the Creative Commons Attribution-NonDerivative-NonCommercial-License, permitting copying and reproduction so long as the original work is given appropriate credit. Contents may not be used for commercial purposes, or adapted, remixed, transformed or built upon. (https://creativecommons.org/licenses/by-nc-nd/4.0/).

Thieme Medical and Scientific Publishers Pvt. Ltd. A-12, 2nd Floor, Sector 2, Noida-201301 UP, India 
surgical procedures. On the other hand, thin biotype as the name suggests is characterized by thin gingival tissue making it delicate and almost translucent in appearance. Such a tissue appears friable, usually having a minimal zone of attachment. Evidence suggests that the thin gingival tissue is less resistant to any inflammatory/traumatic/surgical insult and so it usually exhibits pathological changes like the gingival recession. Furthermore, they are frequently characterized by osseous defects like fenestration and dehiscence. $^{5}$

Gingival biotype is known to have relied upon various factors such as gender, age, growth, tooth shape, tooth size, tooth position, and genetically determined factors. The thicker biotype is predominant in males, whereas the female population comprises of thin, scalloped gingival biotype. On comparing the prevalence of gingival biotypes between different age groups, the thick flat biotype is seen in younger individuals while the older age group shows thin scalloped gingival biotype. Therefore, an accurate diagnosis of gingival tissue biotype is of vital importance in determining an appropriate treatment plan and obtaining a reliable esthetic outcome.

Gingival biotype can be evaluated either by direct visual examination, utilizing a periodontal probe, or by direct measurements using endodontic spreaders, endodontic files, and calipers. ${ }^{6}$

Till now, very few studies have reported the effect of pigmentation on gingival thickness and width. The present study aimed to clinically evaluate gingival thickness and width according to the dental arch and location in pigmented and nonpigmented gingiva.

\section{Materials and Methods}

A total of 240 sites (120 pigmented and 120 nonpigmented gingiva) from systemically healthy subjects, who visited the outpatient department of Guru Nanak Dev Dental College, Sunam, Punjab, were selected for the study. All the selected subjects were given a verbal description of the study and an informed consent was taken.

The inclusion criteria of subjects were as follows: (1) age range between 18 and 25 years, (2) healthy periodontal

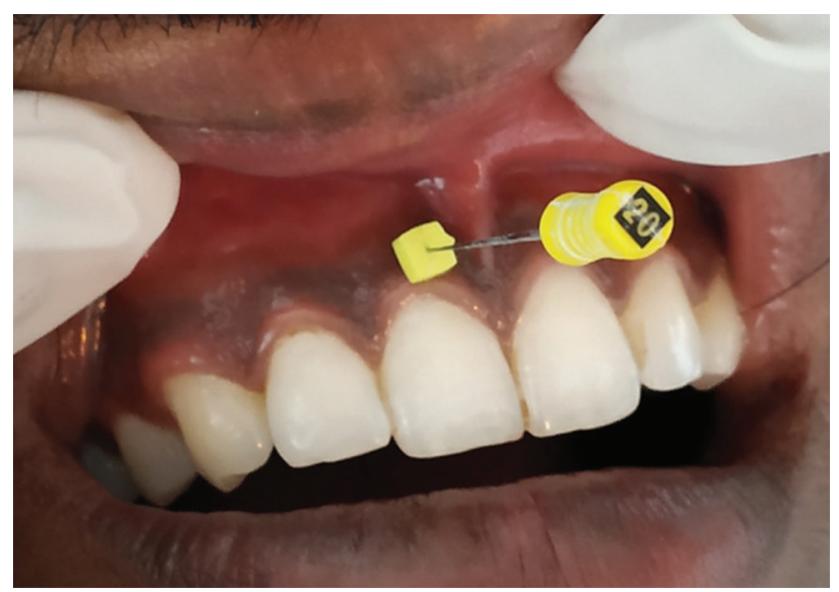

Fig. 1 Measurement of gingival thickness in group 1. tissues with good plaque control, gingival bleeding index (Ainamo and Bay, $1975^{7}$ ) score of $20 \%$, and no loss of attachment, (3) physiologic gingival pigmentation (Dummet's oral pigmentation index [DOPI] score 2-3 [heavy pigmentation]), (4) nonpigmented gingiva with DOPI score (no pigmentation), and (5) presence of normally aligned anterior teeth in both maxilla and mandible.

The exclusion criteria were as follows: (1) pregnancy and lactation, (2) gingival recession in the anterior, (3) participants with prosthesis or any restoration in the anterior maxillary teeth, (4) systemic diseases that are known to cause pathologic pigmentation such as hormonal imbalance, Addison's disease, Peutz-Jeghers syndrome, Ehlers-Danlos syndrome, etc., (5) extensive restorations, (6) use of any medication that can affect the size of gingiva and periodontal tissues such as phenytoin, calcium channel blockers, minocycline, and cyclosporine A, (7) smokers, and (8) tooth malposition and rotation.

\section{Methodology}

After site selection, two groups were formed; that is, group 1 comprising of 120 sites with pigmented gingiva and group 2 comprising of 120 sites with nonpigmented gingiva.

After the initial visit of scaling and root planning, anesthetic gel (LOX 2\% gel) was topically applied on the labial gingiva. To measure the gingival thickness (Figs. 1 and 3), a 20 number endodontic spreader (fitted with a stopper) was inserted perpendicularly at a point at the center of the marginal gingiva and mucogingival junction. Once inserted, the rubber stopper was slid up to the labial aspect of gingiva. After that, it was recorded against a commercially available digital vernier caliper (with a resolution of $0.01 \mathrm{~mm}$ ). Similarly, the gingival thickness was assessed on central incisor (CI), lateral incisor (LI), and canine (C) in both the maxillary and mandibular arch.

To measure the width of keratinized gingiva, a 20 number endodontic spreader (provided with a stopper) was used to measure the distance between gingival margin and mucogingival junction ( - Figs. 2 and $\mathbf{4}$ ) and was recorded against the digital vernier caliper (with a resolution of $0.01 \mathrm{~mm}$ ).

The clinical parameters recorded were then evaluated and put to statistical analysis.

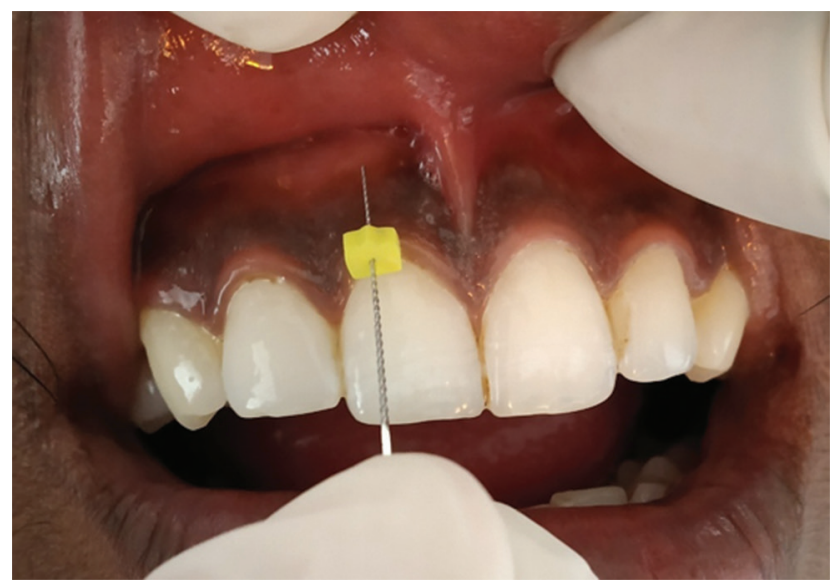

Fig. 2 Measurement of width of keratinized gingiva in group 1. 


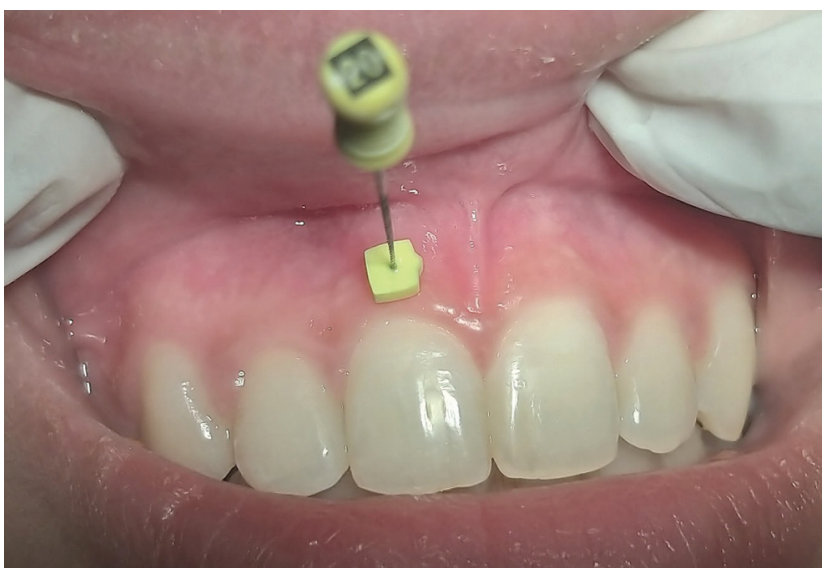

Fig. 3 Measurement of gingival thickness in group 2.

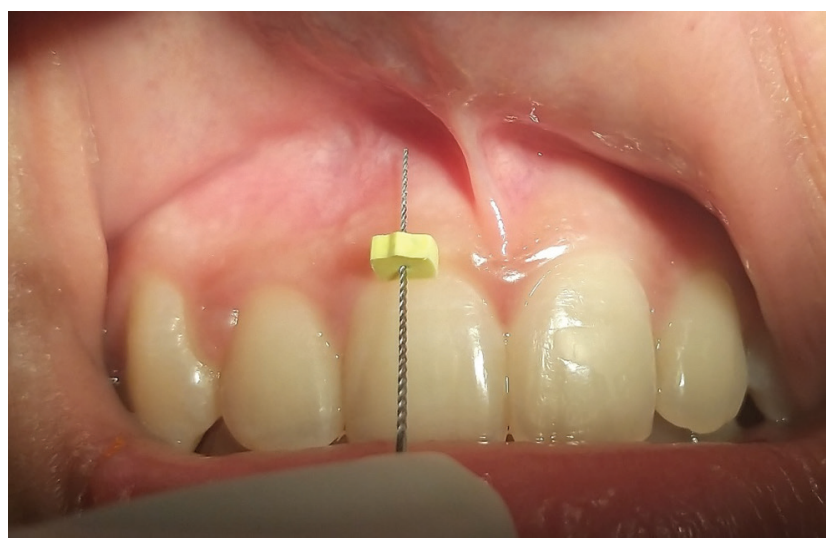

Fig. 4 Measurement of width of keratinized gingiva in group 2.

\section{Results}

The mean thickness of gingiva was found to be $1.51 \pm 0.52$ in group 1 (pigmented group) and $0.99 \pm 0.41$ in group 2 (nonpigmented group) and the difference was found to be statistically highly significant (HS) $(p<0.001)$. Similarly, the width of keratinized gingiva was found to be $2.87 \pm 1.05$ in group 1 and $2.15 \pm 1.00$ in group 2 , and the difference was statistically highly significant ( - Table $\mathbf{1}$ ).

According to arch, the mean thickness and width were found to be more in the maxillary arch (i.e., $1.64 \pm 0.58$ and $3.32 \pm 1.09$ in group 1 and $1.03 \pm 0.46$ and $2.38 \pm 1.06$ in group 2 , respectively) as compared with the mandibular arch (i.e., $1.38 \pm 0.42$ and $2.44 \pm 0.80$ in group 1 and $0.94 \pm 0.36$ and $1.92 \pm 0.87$ in group 2 , respectively). The difference was found to be statistically highly significant in both groups ( $\mathbf{- T a b l e ~} 2$ ).

According to tooth location, the mean gingival thickness in group 1 was found to be $1.58 \pm 0.61$ for CIs, $1.54 \pm 0.51$ for LI, and $1.40 \pm 0.41$ for canine, respectively, whereas in group 2 the mean thickness was observed as $1.06 \pm 0.45$ for $\mathrm{CL}, 1.00 \pm 0.43$ for $\mathrm{LI}$, and $0.91 \pm 0.35$ for canine. The thickness was found to be maximum in $\mathrm{CI}$ and least in $\mathrm{LI}$ in both the groups. However, when the width of keratinized gingiva was observed, it was found to be $2.81 \pm 1.09$ for $\mathrm{CI}, 3.07 \pm 0.93$ for $\mathrm{LI}$, and $2.77 \pm 1.11$ for canine in group 1 , whereas it was $2.29 \pm 1.09$ for CI, 2.19 \pm 0.94 for $\mathrm{LI}$, and $1.96 \pm 0.94$ for canine in group 2 . The mean
Table 1 Showing thickness and width of keratinized gingiva in both the groups

\begin{tabular}{|l|l|l|l|}
\hline & Group 1 & Group 2 & $p$-Value \\
\hline Thickness & $1.51 \pm 0.52$ & $0.99 \pm 0.41$ & Highly significant \\
\hline $\begin{array}{l}\text { Width of } \\
\text { keratinized } \\
\text { gingiva }\end{array}$ & $2.87 \pm 1.05$ & $2.15 \pm 1.00$ & Highly significant \\
\hline
\end{tabular}

Table 2 Showing variation in thickness and width of keratinized gingiva according to dental arch in both the groups

\begin{tabular}{|l|l|l|l|l|}
\hline & & Group 1 & Group 2 & $\boldsymbol{p}$-Value \\
\hline $\begin{array}{l}\text { Maxillary } \\
\text { arch }\end{array}$ & Thickness & $1.64 \pm 0.58$ & $1.03 \pm 0.46$ & $\begin{array}{l}\text { Highly } \\
\text { significant }\end{array}$ \\
\cline { 2 - 5 } & $\begin{array}{l}\text { Width of } \\
\text { keratinized } \\
\text { gingiva }\end{array}$ & $3.31 \pm 1.09$ & $2.38 \pm 1.06$ & $\begin{array}{l}\text { Highly } \\
\text { significant }\end{array}$ \\
\hline $\begin{array}{l}\text { Mandibular } \\
\text { arch }\end{array}$ & Thickness & $1.38 \pm 0.42$ & $0.94 \pm 0.36$ & $\begin{array}{l}\text { Highly } \\
\text { significant }\end{array}$ \\
\cline { 2 - 5 } & $\begin{array}{l}\text { Width of } \\
\text { keratinized } \\
\text { gingiva }\end{array}$ & $2.44 \pm 0.80$ & $1.92 \pm 0.87$ & $\begin{array}{l}\text { Highly } \\
\text { significant }\end{array}$ \\
\hline
\end{tabular}

Table 3 Showing variation in thickness and width of keratinized gingiva according to tooth location in both the groups

\begin{tabular}{|c|c|c|c|c|}
\hline Tooth & & Group 1 & Group 2 & $p$-Value \\
\hline \multirow[t]{2}{*}{$\begin{array}{l}\text { Central } \\
\text { incisor }\end{array}$} & Thickness & $1.58 \pm 0.61$ & $1.06 \pm 0.45$ & $\begin{array}{l}\text { Highly } \\
\text { significant }\end{array}$ \\
\hline & $\begin{array}{l}\text { Width of kerati- } \\
\text { nized gingiva }\end{array}$ & $2.81 \pm 1.09$ & $2.29 \pm 1.09$ & Significant \\
\hline \multirow[t]{2}{*}{$\begin{array}{l}\text { Lateral } \\
\text { incisor }\end{array}$} & Thickness & $1.54 \pm 0.51$ & $1.00 \pm 0.43$ & $\begin{array}{l}\text { Highly } \\
\text { significant }\end{array}$ \\
\hline & $\begin{array}{l}\text { Width of kerati- } \\
\text { nized gingiva }\end{array}$ & $3.07 \pm 0.93$ & $2.19 \pm 0.94$ & $\begin{array}{l}\text { Highly } \\
\text { significant }\end{array}$ \\
\hline \multirow[t]{2}{*}{ Canine } & Thickness & $1.40 \pm 0.41$ & $0.91 \pm 0.35$ & $\begin{array}{l}\text { Highly } \\
\text { significant }\end{array}$ \\
\hline & $\begin{array}{l}\text { Width of kerati- } \\
\text { nized gingiva }\end{array}$ & $2.77 \pm 1.11$ & $1.96 \pm 0.94$ & $\begin{array}{l}\text { Highly } \\
\text { significant }\end{array}$ \\
\hline
\end{tabular}

width was found to be maximum in LI in group 1 (pigmented) and $\mathrm{CI}$ in group 2 (nonpigmented), whereas it was minimum in canine in both the groups (-Table 3 ).

\section{Discussion}

In recent years, the esthetic perception of the gingiva, especially its gingival thickness and width, has become the focus of concern in periodontics from both an epidemiologic and a therapeutic viewpoint. ${ }^{8}$ Across the literature, studies have concluded that gingival biotype plays a vital role in the development of mucogingival problems and the success of treatment for recession and wound healing.

A clinician's comprehension of gingival biotype is of prime importance in gaining ideal treatment outcomes. As reported by Shah et al in 2017, ${ }^{9}$ gingival biotype has two variants, thick and thin gingival biotype. The thick biotype comprises of flat soft tissue and thick bony architecture. This tissue form is more prone to gingival recession due to its thick and fibrotic 
nature. However, thin gingival biotype is delicate, highly scalloped soft tissue with thin bony architecture characterized by bony dehiscence and fenestrations, which is more prone to recession, bleeding, and inflammation. Patients with thin gingival biotype are at high risk of developing gingival or periodontal diseases. Therefore, special consent should be taken from the patients during treatment modalities.

In the current study after anesthetizing the labial gingiva, the gingival thickness was measured by inserting the endodontic spreader (provided with a rubber stopper) at a point in the center of the gingival margin and mucogingival junction and thickness was recorded against the digital vernier caliper (with a resolution of $0.01 \mathrm{~mm}$ ). This method was reported by Kolte et al in $2014^{10}$ who estimated gingival thickness using a similar transgingival probing method using an endodontic spreader. As the alveolar bone varies in thickness on different areas of labial aspect of maxilla and mandible, and the soft tissue always follow the hard tissue, only one point, that is, the center point between gingival margin and mucogingival junction, was chosen so that interindividual variations can be minimized. Similarly, the width of the keratinized gingiva was measured with the help of endodontic spreader as the distance between gingival margin and mucogingival junction and was recorded against the digital vernier caliper with a resolution of $0.01 \mathrm{~mm}$.

In the current study, both gingival thickness and width was found to be more in group 1 (pigmented) than group 2 (nonpigmented) and the difference was found to be statistically highly significant $(p \leq 0.001)$. Similar results have been observed in the study conducted by Bharamappa et al in 2014. ${ }^{11}$

When the mean difference in gingival thickness and width was evaluated according to the dental arch, it was observed that both gingival thickness and width were more in the maxillary arch than mandibular arch in both the groups and the difference was statistically highly significant. The intra-arch comparison shows that both gingival thickness and width was more in group 1 (pigmented) than group 2 (nonpigmented) $(p<0.001)$. Similarly, Müller et al in $2000^{12}$ evaluated the variations in the thickness of gingiva with respect to age, gender, and dental arch location. The study concluded that gingival thickness decreases with age in both maxillary and mandibular arches. The maxillary arch was found to have a thicker gingiva than mandibular arch. Also, the study reported a thicker gingiva in males than females. Vandana and Savitha in $2005^{13}$ also reported similar findings in their study to determine the thickness of gingiva in association with age, gender, and dental arch location. However, in none of these studies, the effect of pigmentation on gingival thickness and width was evaluated. So, probably, the present study is one of those few studies which determine the variation in gingival thickness according to the dental arch in pigmented and nonpigmented gingiva.

When an intergroup comparison was made according to tooth location, it was observed that gingival thickness was found to be maximum in $\mathrm{Cl}$ and minimum in canine in both the groups. However, the width of keratinized gingiva was found to be maximum in $\mathrm{LI}$ in group 1 (pigmented) and $\mathrm{CI}$ in group 2 (nonpigmented), whereas it was minimum in canine in both the groups. These findings were somewhere in accordance to studies conducted by Muller and Eger, ${ }^{14}$ Muller et al, ${ }^{12}$ Egreja et $\mathrm{al},{ }^{15}$ and Bowers ${ }^{16}$ which stated that maximum gingival thickness was observed in $\mathrm{CI}$ followed by $\mathrm{LI}$ and then canine. Vandana et al ${ }^{17}$ conducted a study to evaluate arch and tooth wise, the width of attached gingiva in primary, mixed, and permanent dentitions using UNC-15 probe. Their study concluded that gingival width increases with age and was found to be significantly higher in maxillary permanent dentition (i.e., canine followed by $\mathrm{Cl}$ and then $\mathrm{LI}$ ), whereas no significant difference was reported in primary and mixed dentition.

There are very few studies cited in the literature that have evaluated the variations in gingival thickness and width according to dental arch and location in pigmented and nonpigmented gingiva. The findings of the study further illustrate a positive correlation between gingival thickness and width and pigmentation. The maxillary arch was found to have thicker gingiva than a mandibular arch. As thin gingiva is more susceptible to gingival recession because of the decreased blood supply to the underlying bone, careful treatment planning is required for the successful outcome of regenerative periodontal therapy.

\section{Note}

This study was presented at the 18th ISP PG Convention, Jaipur, April 19-21, 2019.

\section{Conflict of Interest}

None declared.

\section{References}

1 Claffey N, Shanley D. Relationship of gingival thickness and bleeding to loss of probing attachment in shallow sites following nonsurgical periodontal therapy. J Clin Periodontol 1986;13(7):654-657

2 Zigdon H, Machtei EE. The dimensions of keratinized mucosa around implants affect clinical and immunological parameters. Clin Oral Implants Res 2008;19(4):387-392

3 De Rouck T, Eghbali R, Collys K, De Bruyn H, Cosyn J. The gingival biotype revisited: transparency of the periodontal probe through the gingival margin as a method to discriminate thin from thick gingiva. J Clin Periodontol 2009;36(5):428-433

4 Malhotra R, Grover V, Bhardwaj A, Mohindra K. Analysis of the gingival biotype based on the measurement of the dentopapillary complex. J Indian Soc Periodontol 2014;18(1):43-47

5 Joshi N, Agarwal MC, Madan E, Gupta S, Law A. Gingival biotype and gingival bioform: determining factors for periodontal disease progression and treatment outcome. Int J Sci Stud 2016;4(3):220-225

6 Manjunath RG, Rana A, Sarkar A. Gingival biotype assessment in a healthy periodontium: transgingival probing method. J Clin Diagn Res 2015;9(5):ZC66-ZC69

7 Ainamo J, Bay I. Problems and proposals for recording gingivitis and plaque. Int Dent J 1975;25(4):229-235

8 Tasneem S, Venugopal K, Ravishankar PL, Chakraborty P, Kandukuri VG, Saravanan AV. Determining the gingival biotype based on dentopapillary compound. J Int Clin Dent Res Organ 2018;10(1):37

9 Shah DS, Duseja S, Vaishnav K, Shah RP. Adaptation of gingival biotype in response to prosthetic rehabilitation. Adv Hum Biol 2017;7(2):85 
10 Kolte R, Kolte A, Mahajan A. Assessment of gingival thickness with regards to age, gender and arch location. J Indian Soc Periodontol 2014;18(4):478-481

11 Bharamappa R, Laxman VK. Comparative assessment of gingival thickness in pigmented and nonpigmented gingiva. J Int Clin Dent Res Organ 2013;5(1):19

12 Müller HP, Heinecke A, Schaller N, Eger T. Masticatory mucosa in subjects with different periodontal phenotypes. J Clin Periodontol 2000;27(9):621-626

13 Vandana KL, Savitha B. Thickness of gingiva in association with age, gender and dental arch location. J Clin Periodontol 2005; 32(7):828-830
14 Müller HP, Eger T. Gingival phenotypes in young male adults. J Clin Periodontol 1997;24(1):65-71

15 Medina Coeli Egreja A, Kahn S, Barceleiro M, Bittencourt S. Relationship between the width of the zone of keratinized tissue and thickness of gingival tissue in the anterior maxilla. Int J Perio Rest Dent 2012;32(5):x

16 Bowers GM. A study of the width of attached gingiva. J Periodontol 1963;34(3):201-209

17 Vandana KL, Shivani S, Savitha B, Vivek HP. Assessment of gingival sulcus depth, width of attached gingiva, and gingival thickness in primary, mixed, and permanent dentition. J Dent Res Rev 2017;4(2):42 